\title{
Uma leitura Dworkiana dos feriados e dias sagrados brasileiros no contexto da laicidade
}

\author{
A Dworkian understanding of brazilian holydays and sacred dates in the context of secularity
}

\author{
Rodrigo Pedroso Barbosa ${ }^{1}$ (D) e Edson Vieira da Silva Filho ${ }^{3}$ (D) \\ ${ }^{1}$ Faculdade de Direito do Sul de Minas, mestre em Direito pela Faculdade de Direito do Sul de Minas, email: rodrigo@ direito.pro \\ ${ }^{2}$ Faculdade de Direito do Sul de Minas, pós doutor em Direito pela Unisinos, doutor em direito pela Unesa, evsilvaf@globo.com
}

\section{RESUMO}

O presente trabalho visa, através de uma análise do referencial teórico e o emprego do método bibliográfico, realizar um estudo sobre a relação de feriados e dias sagrados oficiais existentes no Brasil com o modelo de laicidade do Estado. Para tal, inicia-se com uma revisão e análise das origens dos feriados e dias sagrados oficiais no Brasil, tanto no plano constitucional como legal. Buscando compreender as diferentes facetas do tema, os feriados também são analisados na perspectiva do direito do trabalho e enquanto manifestações culturais. Por último, através do aporte das teoria de Ana Lomtatidze, tenta-se encontrar modelos de propostas para o tratamento do tema no Brasil. Conclui-se que, apesar de dois dos modelos propostos serem constitucionalmente possíveis dentro da ordem constitucional vigente, nenhum é totalmente adequado, sendo necessário o desenvolvimento de uma teoria da laicidade pátria que possibilite lidar com a questão de forma adequada à constituição, que representa a principal expressão da moralidade política brasileira. Com este fim, faz-se a leitura através do marco teórico de Ronald Dworkin, com importantes aportes de Jónatas Machado e Ana Lomtatidze. Sendo impossível uma solução imediata para tema tão amplo, finaliza-se com uma reconstrução sistêmica dos conceitos basilares para se que possa prosseguir com a discussão sobre o processo de laicização, algo continuo, sujeito a falhas, abusos, avanços e retrocessos, e deve sempre ser monitorado e aprimorado, mas que, para tal, necessita de pontos comuns para discussão e diagnósticos de suas fragilidades, o que se espera germinar com o presente e, ao mesmo tempo, apontar possíveis caminhos a serem seguidos em futuras pesquisas.

Palavras-chave: Direitos Fundamentais. Feriados. Laicidade. Secularidade.

\begin{abstract}
The current work aims to, through an analysis of the theoretical reference and the bibliographical method, implement a study of the relationship between official holydays and sacred dates in Brazil and a secular state model. To that end, we begin with a review and analysis of the origins of the official holydays and sacred dates in Brazil, both in the constitutional and legal frames. In trying to understand the different facets of the issue, the holydays are also analyzed in relation to labor law and as cultural manifestations. Lastly, with inputs from Ana Lomtatidze theories, proposals for different models to deal with the issue in Brazil are considered. The conclusion is that, even if two of those models are constitutionally possible within the current constitutional order, none is wholly adequate, and it is needed to develop a laicity theory specific to deal with the issue in a manner that is adequate to the constitution, which represents the main expression of the Brazilian political morality. Toward this goal, Ronald Dworkin was selected as the main theoretical reference, with relevant input from Jónatas Machado e Ana Lomtatidze. Being impossible to present a solution on such an extensive theme, this work closes with a systemic reconstruction of the basic concepts presented, so to begin a discussion on the laicization process as something ongoing, subject to failures, abuses, advancements and setbacks, and something that requires constant monitoring and improvements but that, to that end, need an common grounds for discussions and a diagnostic of its frailties, hopefully seeded with this text and, at the same time, point toward possible venues to be addressed in future researchs.
\end{abstract}

Keywords: Fundamental Rights. Holydays. Laicity. Secularity. 


\section{INTRODUÇÃO}

Do latim lat feriatus, o substantivo masculino feriado significa "dia em que se descansa, se suspende o trabalho, por prescrição civil ou religiosa". Enquanto adjetivo, é a "hora, período ou dia em que não se trabalha, que se dedica ao repouso ou lazer" (MICHAELIS, 2017).

A tradição histórica de existência de feriados pode ser traçada aos primórdios da humanidade, com suas origens e justificações tão diferentes como as culturas em que ocorreram. Dia sagrados e datas nacionais comemorativas (frequentemente com ares patrióticos e nacionalistas) são duas origens comuns, mas de qualquer forma assim restritas. E, assim como duas origens diferentes, também com diferentes significados. E, em uma cultura produtiva (e produtora), eventualmente ligadas ao exercício do trabalho.

Outros desdobramentos também são inevitáveis. Frequentemente são comemorações, com algum tipo de ritualística e iconografia envolvidos. Frequentemente atividades familiares ou públicas. De pequena escala, dentro do lar, ou em eventos gigantescos de escopo internacional e envolvendo quantias suntuosas de dinheiro (e.g.: Carnaval). Podem estar vinculados às mais importantes tradições de uma dada religião (e.g.: Natal), ou aos mais fundamentais valores de um país (e.g.: Dia da Independência). E podem, ainda, enquanto homenagem, representar a externalização de um valor importante para o Estado e a sociedade (e.g.: Dia Internacional da Mulher), ainda que não seja um feriado.

O presente trabalho tem por objetivo melhor compreender a relação de feriados e dias sagrados oficiais existentes no Brasil com o modelo de laicidade do Estado, o que é desenvolvido através da análise dos referenciais teóricos, em particular Ronald Dworkin, marco teórico utilizado, empregando-se o método de pesquisa bibliográfica, com aportes teórico das obras de Jónatas Machado e Ana Lomtatidze, aplicada ao constitucionalismo brasileiro, e com apoio de referenciais nacionais e internacionais compatíveis com os marcos selecionados e apropriados à realidade latino-americana, em geral, e brasileira, em específico.

\section{FERIADOS NA ORDEM CONSTITUCIONAL}

Feriados foram primeiramente introduzidos no texto constitucional pátrio na Constituição de 1937 (BRASIL, 1937), em um dispositivo que veio a ser suspenso pelo Decreto $\mathrm{n}^{\circ}$ 10.385/1942. Redação bastante semelhante seria incluída nas constituições de 1946, 1967 e na 1969 (Emenda 
Constitucional 1), essencialmente afirmando o direito do trabalhador a descanso remunerado nos feriados civis e religiosos (com pequenas variações textuais) (BRASIL, 1969).

A Constituição de 1988, por outro lado, não faz referência direta a feriados, embora os reconheça indiretamente, sem maiores especificidades, em normas que indicam alguns de seus efeitos, como por exemplo indicando que reuniões do Congresso Nacional marcadas para datas que recaírem sobre feriados devem ser transferidas para o primeiro dia útil subsequente (BRASIL, 1988), tendo relegado a questão para a legislação infraconstitucional.

O marco inicial legislativo vigente é a Lei 605/49 que, ominosamente, trata do "Repouso semanal remunerado e o pagamento de salário nos dias feriados civis e religiosos" (BRASIL. Lei $\mathrm{n}^{\circ} 605 \ldots$, 1949). Embora originariamente oferecesse o conceito do que seria um feriado religioso, em seu artigo 11 - os dias de guarda, declarados em lei municipal, de acordo, com a tradição local -, inicialmente limitados a 7 e depois 4 (neste caso, incluindo especificamente a Sexta-Feira da Paixão, em alteração pelo Decreto-Lei 86/66), este artigo foi totalmente revogado em 1995 pela lei 9.093 (BRASIL. Lei $\mathrm{n}^{\circ}$ 9.093..., 1995) que se incube especificamente de dispor sobre feriados. A lei 605/49 foi regulamentada pelo Decreto 27.048/49 (BRASIL. Decreto n 27.048..., 1949), com uma característica bastante peculiar: apesar de reconhecer o descanso ao trabalhador em feriados religiosos, as instituições religiosas ficaram explicitamente isentas desta regra, sendo nessas permitido o trabalho.

Pouco após ao marco inicial, a Lei 662/49 (BRASIL. Lei n 662..., 1949) decreta, em sua redação originária, feriados nacionais as datas de $1^{\circ}$ de janeiro, $1^{\circ}$ de maio, 7 de setembro, 15 de novembro e 25 de dezembro. Posteriormente, através da Lei 10.607/2002, seriam adicionadas as datas de 21 de abril e 2 de novembro (BRASIL. Lei n $\left.{ }^{\circ} 10.607 . . ., 2002\right)$, para o cabalístico número de 7. Além disso, estabelece regras limitando os pontos facultativos decretados pelos estados, Distrito Federal e municípios.

Em 30 de junho 1980, o então presidente João Figueiredo promulgou a Lei n 6.082. Esta legislação possui grande relevância para a questão da laicidade, pois não apenas declara como feriado nacional o dia 12 de outubro, como declara Nossa Senhor Aparecida como Padroeira do Brasil e indica que a data será para “culto público e oficial” (BRASIL. Lei n 6.802..., 1980). Tal lei continua em vigor.

O principal marco legislativo atual sobre a existência e estabelecimento de feriados é a lei 9.093 de 1995 (BRASIL. Lei n 9.093..., 1995). Em parte:

Ciências Sociais Aplicadas em Revista, v. 20, n. 38, p. 186-202, semestral, janeiro-junho, 2020. 
O PRESIDENTE DA REPÚBLICA Faço saber que o Congresso Nacional decreta e eu sanciono a seguinte Lei:

Art. $1^{\circ}$ São feriados civis:

I - os declarados em lei federal;

II - a data magna do Estado fixada em lei estadual.

III - os dias do início e do término do ano do centenário de fundação do Município, fixados em lei municipal. (Inciso incluído pela Lei $\mathrm{n}^{\circ}$ 9.335, de 10.12.1996)

Art. $2^{\circ}$ São feriados religiosos os dias de guarda, declarados em lei municipal, de acordo com a tradição local e em número não superior a quatro, neste incluída a SextaFeira da Paixão.

Observam-se duas situações peculiares. A primeira é o artigo segundo reconhecer explicitamente feriados religiosos, em redação bastante semelhante à presente nas constituições anteriores, remetendo-se à de 1937, inclusive quanto a obrigatoriedades da Sexta-Feira da Paixão. A segunda é que, como observado, apesar de serem classificados como feriados civis, existem feriados religiosos declarados em lei federal (e.g. 25 de dezembro). Assim, a lei 9.093 dará dupla legitimidade, além de legalidade, ao estabelecimento de feriados religiosos.

Bernardo Gonçalves Fernandes elabora sobre a questão dos feriados religiosos na ordem constitucional:

Questão dos feriados religiosos: conforme o $\$ 2^{\circ}$ do art. 215 da CR/88 a lei disporá sobre a fixação de datas comemorativas de alta significação para os diferentes segmentos étnicos nacionais. Nesse sentido, a legislação infraconstitucional pode determinar a existência de feriados, incluindo os de apelo cultural ou mesmo os de cunho religioso. Porém, boa parte da doutrina questiona se seria adequado em país um laico a existência de feriados de cunho cristão como a Páscoa, corpus christi ou mesmo natal (FERNANDES, 2017, p. 447).

A identificação da absoluta preponderância de feriados religiosos católicos não apresenta dificuldades ${ }^{1}$. E, como aponta Dworkin (2009, p. 151), argumentos teológicos para tal devem ser rejeitados, não devendo ter validade jurídica. Argumentos históricos e de tradição também são no mínimo suspeitos, vez que, como aponta Jónatas Machado, isto seria uma justificativa que defenderia um estatuto jurídico e político privilegiado alcançado pela posição sociologicamente dominante da Igreja Católica (MACHADO, 2002, p. 154).

Seria, assim, uma tradição criada através do poder de influência (DWORKIN, 2005, p. 263) da Igreja Católica, e não desenvolvida naturalmente pelo povo, resultando não em liberdade, mas uma violação da igualdade (DWORKIN, 2005, p. 79). Merece destaque o aviso de Jónatas Machado sobre esta desigualdade, quando alerta que o reconhecimento do fato de que, ao promover o

\footnotetext{
${ }^{1}$ E.g., a já mencionada Portaria 369/2016 do Ministério do Planejamento.
} 
abandono de práticas regulatórias desiguais, está se contribuindo decisivamente para a eliminação de atitudes e preconceitos discriminatórios, enraizados e sistemáticos (MACHADO, 2002, p. 154). E, como afirma Dworkin (2005, p. IX), “[n]enhum governo é legítimo a menos que demonstre igual consideração pelo destino de todos os cidadãos sobre os quais afirme seu domínio e aos quais reivindique fidelidade”. Violar essa igualdade é violar a legitimidade do governo.

\section{FERIADOS, O TRABALHADOR, PREPONDERÂNCIA CULTURAL E LAICIDADE}

O conceito de feriado está inexoravelmente ligado ao trabalho desde o seu nascimento. Ou, mais precisamente, do não-trabalho. Seja por prescrição civil ou religiosa, é quando se descansa e se dedica a outras atividades. Feriados religiosos frequentemente envolvem práticas específicas, ou vedações a atividades, obrigatórias para seguidores.

Inicialmente, verifica-se o direito ao descanso como basilar ao trabalhador. O repouso semanal remunerado, preferencialmente aos Domingos, está presente no artigo $7^{\circ}$ da Constituição de 1988. A Consolidação das Leis do Trabalho (BRASIL. Decreto-Lei n 5.452..., 1943), em seu artigo 70, traz vedação ao trabalho em feriados nacionais e feriados religiosos, para em seu artigo $227, \S 2^{\circ}$, afirmar que o trabalho aos domingos, feriados e dias santos de guarda é extraordinário. Menções a feriados, feriados religiosos e dias santos de guarda são feitas novamente no artigo 229, $\S 2^{\circ}$, artigo $249, \S 1^{\circ}$ e artigo 385 , parágrafo único.

E, se o direito a descanso do trabalhador é um direito fundamental social, como atestado por estar presente no Título II da Constituição, a redução de seu direito ao descanso é algo a ser evitado, pois implicaria em um exercício do poder do Estado diretamente dentro da esfera pessoal do indivíduo.

Mais ainda, como leciona Dworkin (2007, p. 419), este direito deve ser realizado igualmente para todos:

\footnotetext{
O governo deve não somente tratar as pessoas com consideração e respeito, mas com igual consideração e igual respeito. Não deve distribuir bens ou oportunidades de maneira desigual, com base no pressuposto de que alguns cidadãos têm direito a mais, por serem merecedores de maior consideração. O governo não deve restringir a liberdade, partindo do pressuposto de que a concepção de um cidadão sobre a forma de vida mais adequada para um grupo é mais nobre ou superior do que a de outro cidadão.
}

Disto, tiram-se duas conclusões importantes. A primeira é de que o governo não pode retirar direitos arbitrariamente. E outra, mais importante, é que um determinado grupo, por qualquer 
argumento, não pode receber mais direitos e mais consideração por ser mais nobre ou superior. Este último se liga diretamente aos feriados religiosos e, ainda mais, aos dias santos de guarda. Não se pode negar que cada lei é o produto do seu tempo, e a Consolidação das Leis do Trabalho é de 1943, um dos períodos de maior influência da Igreja Católica sobre o governo brasileiro no século $\mathrm{XX}$ :

Com Getúlio Vargas, o catolicismo recupera sua proeminência e ascendência sobre o Estado, notadamente na área trabalhista.

$[\ldots]$

No caso brasileiro, tratava-se de uma verdadeira restauração católica, a fé católica era a religião oficial e oficia do país, ainda que sem concordata.

[...]

Os Círculos Operários, a Juventude Operária Católica, rebentos da Rerum Novarum, funcionavam como motores de animação e inserção da classe trabalhadora na estrutura clerical-sindical-estado-novista. O Estado religioso católico opera como interlocutor do outro Estado, cristão e anticomunista, quer dirigir os movimentos (sociais e sindicais) dos assalariados urbanos e rurais e controlar como mediador mandatário a relação capitaltrabalho; politicamente o escopo é cobiçoso: operar institucionalmente no combate direto ao crescente inconformismo social e operário; tudo isso redundaria numa solução social cristã, a acalentada e tão sonhada via entre comunismo e capitalismo. Como monopolizadora do divino e proprietária da transcendência da humanidade, Roma defendia a reconciliação com o capitalismo, sujeitando-o teologicamente às formações econômico-sociais existentes (MIR, 2007, p. 122-123).

Pouco surpreende, neste contexto, a inserção dos dias santos de guarda na legislação trabalhista. Porém, tal preceito sobrevive, não apenas na Consolidação das Leis do Trabalho, mas também em outras legislações surgidas na vigência da atual ordem constitucional, como o artigo $2^{\circ}$ da lei 9.093/95 que afirma serem feriados religiosos os dias de guarda, declarados em lei municipal (BRASIL. Lei $\mathrm{n}^{\circ}$ 9.093..., 1995), com a pequena concessão da exclusão do adjetivo santificador.

A questão da natureza e da preponderância da tradição religiosa majoritária é também abordada por Maurício Godinho Delgado (2017, p. 1100-1101), quando define feriados religiosos:

Feriados Religiosos - Os feriados religiosos são comemorativos de datas relevantes à tradição religiosa dominante no País (ilustrativamente, 12 de outubro - Nossa Senhora Aparecida; Sexta-feira da Paixão; 25 de dezembro, Natal), ou dominante na comunidade local. A ordem jurídica define-os como "dias de guarda, declarados em lei municipal, de acordo com a tradição local" (antigo art. 11, Lei n. 605/49; na mesma linha, Lei n. 9.093/95).

A maioria dos feriados religiosos é declarada em lei municipal, a teor de autorização normativa de lei federal (antigo art. 11 da Lei n. 605/49; atual Lei n. 9.093/95). Há, contudo, feriados religiosos declarados em lei federal. É o que se passa com o feriado de 12 de outubro (dia da Padroeira do Brasil, Nossa Senhora Aparecida), fixado pelo diploma federal n. 6.802, de 1980. Do mesmo modo, assim ocorre com o feriado do Natal, 25 de dezembro (Lei n. 662, de 1949). Recentemente, o dia de finados (2 de novembro), típico feriado municipal, passou a feriado nacional (Lei n. 10.607/2002, conferindo nova redação

Ciências Sociais Aplicadas em Revista, v. 20, n. 38, p. 186-202, semestral, janeiro-junho, 2020. 
ao art. $1^{\circ}$ da Lei n. 662/1949). A lei federal também, de certa maneira, demarcou a Sextafeira da Paixão como feriado: é que estabeleceu que este dia se incluía no rol máximo de quatro feriados religiosos que poderiam ser declarados por lei municipal (antigo art. 11, Lei n. 605; hoje, Lei n. 9.093/95). (ênfase nossa)

Aponta, ainda, que originalmente apenas dois feriados nacionais tinham caráter religioso "Padroeira do Brasil" e Natal -, aos quais agora também se acrescenta o Dia de Finados. Ainda: "que a Sexta-feira da Paixão, embora seja declarada feriado pelas leis municipais, tende a ser observada genericamente em todo o País (a própria lei federal, como visto, engloba este dia no rol dos feriados a serem declarados por lei municipal)" (DELGADO, 2017, p. 1101).

Esta definição e, em alguns casos, redefinição de feriados acaba sendo um reflexo de uma realidade de influências de poder, como aponta Bosisio (2016, p. 57):

\begin{abstract}
No processo legislativo, o jogo que se forma pode exibir pequenas alterações no calendário ou em norma vigente, supressões ou inclusões de feriados, redefinições do significado de uma mesma ata, apresentação de proposta idêntica em projetos distintos. Tudo isso faz parte das suas estratégias, seja para reforçar alguma proposta, produzir novos marcos e efeitos, seja apenas para enquadrar no regimento interno da Câmara. No tocante às redefinições de uma data, estas podem significar diferentes maneiras de denominar nuances que revelam distintos contextos e concepções em jogo. Como exemplo, podemos destacar que o dia 25 de dezembro, que inicialmente representava a unidade espiritual dos povos cristãos e depois passou a se referir ao Natal. Já o dia 12 de outubro mudou de significado: antes dizia respeito à descoberta da América e depois se transformou no feriado de Nossa Senhora Aparecida.
\end{abstract}

Godinho aponta ainda que a quase-totalidade dos feriados municipais é religiosa, bem como a previsão de apenas um feriado estadual, a data da carta magna (DELGADO, 2017, p. 1101). Entretanto, existem também um número de datas comemorativas religiosas fixadas em legislação estadual e distrital. Algumas merecem destaque e comentário.

No Acre, o dia 23 de janeiro é feriado do "Dia do evangélico" (ACRE, 2004). Em Alagoas, 24 e 29 de junho são, respectivamente, dia de São João e São Pedro (ALAGOAS, 1993). No Distrito Federal, define 30 de novembro como feriado (DISTRITO FEDERAL. Lei n. 963..., 1995), anteriormente instituída como data comemorativa do "Dia do evangélico" (DISTRITO FEDERAL. Lei n. 893..., 1995). Na Paraíba, 5 de agosto é dia de Nossa Senhora das neves, padroeira do estado, que coincide com o feriado comemorativo à fundação do Estado (PARAÍBA, 1967). No Rio de Janeiro (2008), 23 de abril é Dia de São Jorge.

Esta última, lei do Rio de Janeiro, é atualmente objeto de questionamento quanto a sua constitucionalidade no Supremo Tribunal Federal, na Ação Direta de Inconstitucionalidade 4092 (BRASIL. Supremo Tribunal Federal, 2017), proposta pela Confederação Nacional do Comércio 
de Bens, Serviços e Turismo (CNC). Apesar de fundada na ideia do possível prejuízo econômico para o estado "enquanto os demais estados estão trabalhando", a arguição de inconstitucionalidade é apresentada com base de que "a criação de um feriado religioso de âmbito estadual não encontra amparo na Constituição Federal nem na lei Federal que disciplina a matéria, a Lei $n^{\circ} 9.093$ de setembro de 1995". ${ }^{2}$ Em nenhum momento a questão da laicidade, ou tratamento favorecido à uma determinada religião é mencionada, exceto para louvar a iniciativa da homenagem.

Na ADI 4092 ingressou ainda, como amicus curie, a Congregação Espírita Umbandista do Brasil, defendendo o feriado como ação afirmativa para reforço de identidade, vez que São João é uma das figuras mais cultuadas pelas religiões de matriz afro-brasileiras. ${ }^{3}$ Também participam como amicus curie a Federação do Comércio de Bens, Serviços e Turismo do Estado do Rio de Janeiro e a Federação das Indústrias do Estado do Rio de Janeiro (Firjan).

A questão dos feriados religiosos, conforme pode ser observado pela controvérsia da ADI 4092, é um monstro de diversas cabeças. Envolve questões econômicas, trabalhistas, e mesmo religiosas. Como apontado por Godinho, é definida pela tradição dominante no país, uma ideia que entra em conflito direto com o conceito de laicidade. Mesmo na ausência de feriado trabalhista, a existência de dias de homenagem cria uma hierarquia entre as religiões, criando uma categoria de religião de primeira classe, e as demais.

Tal conclusão de seletividade é demonstrável. Ao passo de que existem outros feriados de homenagens tanto na esfera federal (e.g. Tiradentes) como estadual, esses nunca são de natureza religiosa, com a exclusiva exceção de feriados ligados à tradição da Igreja Católica. Feriados ligados, por exemplo, à tradição africana se limitam a comemorar a "Morte de Zumbi dos Palmares" (Alagoas) ou "Dia da Consciência Negra" (Amazonas, Mato Grosso e Rio de Janeiro). O feriado dos "Mártires de Cunhaú e Uruaçu", do Rio Grande do Norte, é essencialmente outro feriado religioso, que comemora os 30 cristãos martirizados no interior do estado durante as invasões holandesas (atualmente em processo de canonização pela Igreja Católica).

\footnotetext{
2 Trata-se de processo em autos físicos. O teor da petição inicial digitalizada pode ser acessado pela página de acompanhamento supra indicada, podendo também ser visualizada diretamente em http://redir.stf.jus.br/paginadorpub/paginador.jsp?docTP=TP\&docID=447172\#0\%20-\%20Peti\%E7\%E3o\%20inicial. Acesso: 11 ago. 2017.

3 Petição disponível pela página de acompanhamento, e também diretamente em http://redir.stf.jus.br/paginadorpub/paginador.jsp?docTP=TP\&docID=447174\#5\%20-

$\% 20$ Peti\%E7\%E3o\%20(99682/2008)\%20-\%20CEUB\%20-\%20requer\%20ingresso\%20\%22amicus\%20curiae\% 22. Acesso em: 11 ago. 2017.
} 
Não se pode deixar de notar, por último, que o Dia Nacional de Combate à Intolerância Religiosa (BRASIL. Lei n 11.635..., 2007), data comemorativa oficial, não é feriado.

\title{
4 IGUALDADE, EQUIDADE E NEUTRALIDADE: POSSÍVEIS MODELOS
}

Godinho (2017, p. 1088) contextualiza feriados para o Direito do Trabalho, juntamente e, ao mesmo tempo, diferenciando do descanso semanal:

\begin{abstract}
Os feriados, por sua vez, definem-se, no Direito do Trabalho, como lapsos temporais de um dia, situados ao longo do ano-calendário, eleitos pela legislação em face de datas comemorativas cívicas ou religiosas específicas, em que o empregado pode sustar a prestação de serviços e sua disponibilidade perante o empregador.

Os feriados têm características semelhantes àquelas próprias aos descansos semanais. Ilustrativamente, duração de 24 horas (embora no feriado a referência temporal seja o dia e não o conjunto de horas, como ocorre com o d.s.r.); interrupção da prestação de serviços; objetivos pessoais, familiares e sociais semelhantes (embora os dos feriados sejam objetivos mais específicos, enquanto os do repouso semanal, mais genéricos).

São os feriados, entretanto, ao contrário dos descansos semanais, lapsos temporais não rotineiros, verificados apenas em função da ocorrência de datas festivas legalmente tipificadas. (ênfase nossa)
\end{abstract}

Observa-se assim que o feriado, mais do que apenas uma interrupção da prestação de serviços, possui funções e objetivos de natureza pessoais, familiares e sociais. E, garantido o direito de culto, é inegável que este aí também se insere. Demonstrável ainda é a preferência do descanso semanal aos domingos, dia sagrado da tradição da Igreja Católica, presente no texto constitucional. Porém, o domingo não é de nenhuma forma universal.

No Judaísmo, o dia de descanso semanal, o Shabat (Chabad-Lubavitch..., 2017), é observado do pôr-do-sol de sexta-feira ao pôr-do-sol do sábado (Shamash, 2017). O mesmo período é observado também por algumas religiões cristãs, como os Adventistas do Sétimo Dia e Batistas do Sétimo Dia. Durante este período, diversas atividades são proibidas (Shamash, 2017). Quanto aos feriados e dias sagrados, estes são tão numerosos como o número de religiões existentes, com as mais diversas práticas, prescrições e proibições, cujo estudo detalhado em muito ultrapassaria o escopo do presente trabalho.

Assim, observa-se que o atual ordenamento, visando garantir a liberdade de crença e culto, desempenha tal papel direta e fundamentadamente, porém somente para uma única religião, a Católica. Ainda que tais feriados e descansos beneficiem outras religiões, isto ocorre de maneira incidental (e as vezes, poderia se dizer, acidental), vez que, por exemplo, grande parte das religiões 
cristãs terão seus dias santos coincidentes com da Igreja Católica, e grande parte das religiões de matriz africana incorporaram a tradição católica dentro de suas próprias práticas. Na petição para ingressar como amicus curie na ADI 4092, antes mencionada, a Congregação Espírita Umbandista do Brasil esclarece:

[...] o dia de São Jorge, devido ao secular sincretismo religioso, é cultuado tanto na Umbanda como no Candomblé, duas das maiores religiões de matriz africana em número de adeptos em nosso país: a) na Umbanda, no Rio de Janeiro, Rio Grande do Sul e São Paulo são Jorge é identificado como Ogum; b) No Candomblé, no Rio de Janeiro, São João é identificado como o Orixá Ogum. Na Bahia, os adeptos do Candomblé, o identificam com o Orixá Oxossi.

[...] A expressiva massa de praticantes de religiões de matriz africana são os afrobrasileiros, e que São Jorge (ou Ogum) é uma das suas mais cultuadas entidades e/ou Orixás $[\ldots]{ }^{4}$

Ainda que se reconheça tal sincretismo religioso em relação às tradições da Igreja Católica, este é presente apenas em uma pequena parcela de religiões. Essencialmente, as que desta de alguma forma se derivaram (pós calvinismo e reforma protestante), das que dessa assimilaram (como no caso das de matriz africana), ou que possuam certas origens comuns (tradição abraãmicocristã). Assim, se de um lado a presença de feriados religiosos ajuda a garantir o direito à liberdade de culto, por outro esta ocorre de forma a privilegiar certas tradições, em detrimento de todas as demais.

A posição privilegiada da tradição católica dentro da garantia do direito de culto é, novamente, demonstrada pela própria construção normativa, a exemplo da portaria ${ }^{\circ} 369$ de 2016 , do Ministério do Planejamento, Desenvolvimento e Gestão. Em seu artigo $1^{\circ}$ ficam definidos feriados nacionais, dentre eles os civis e os religiosos, exclusivamente de tradição católica. Os demais dias de guarda de credos e religiões são, por sua vez, mencionado no artigo $3^{\circ}$, não como feriados, mas como passíveis de compensação e, mesmo assim, somente se autorizados pelo responsável pela unidade administrativa: "[o]s dias de guarda dos credos e religiões, não relacionados nesta Portaria, poderão ser compensados [...] desde que previamente autorizados pelo responsável pela unidade administrativa de exercício do servidor" (BRASIL. Ministério do Planejamento, 2016)

\footnotetext{
${ }^{4}$ Petição disponível pela página de acompanhamento da ADI 4092, anteriomente citada, e também diretamente em http://redir.stf.jus.br/paginadorpub/paginador.jsp?docTP=TP\&docID=447174\#5\%20\%20Peti\%E7\%E3o\%20(99682/2008)\%20-\%20CEUB\%20-\%20requer\%20ingresso\%20\%22amicus\%20curiae\% 22. Acesso em: 11 ago. 2017.
} 
O argumento de Godinho (2017, p. 1100) de que se trata da tradição dominante do país não pode ser aceito pois, como claramente apontado por Machado, isto foi alcançado através do exercício da posição socialmente dominante da Igreja Católica no país, e, portanto, se aceito, apenas iria perpetuar uma situação de injustiça (MACHADO, 2002, p. 154).

Resta a questão inerente ao direito à igualdade, aqui relevante tanto no prisma dos direitos trabalhistas, do próprio feriado, quanto ao direito à liberdade de crença e culto, como consequência do feriado, "objetivos pessoais, familiares e sociais" (DELGADO, 2017, p. 1088). Para Dworkin (2007, p. 240), este direito abstrato à igualdade pode ser compreendido em dois direitos distintos: direito ao igual tratamento e direito a ser tratado como igual:

$\mathrm{O}$ primeiro deles é o direito a igual tratamento (equal treatment), isto é, à mesma distribuição de bens e oportunidades que qualquer outra pessoa possua ou receba. [...] $\mathrm{O}$ segundo é o direito a ser tratado como igual (treatment as an equal). Este é o direito, não a uma distribuição igual de algum bem ou oportunidade, mas o direito a igual consideração e respeito na decisão política sobre como tais bens e oportunidade serão distribuídos.

No caso, observa-se o primeiro direito quando se fala das mesmas oportunidades, no caso primeiramente identificado ao direito trabalhista ao feriado, ao descanso, ao não trabalho. Se observado somente por este prisma, enquanto o trabalhador tenha seu feriado e todos o tenham em quantidade igual, a motivação para tal - se civil ou religioso e, se religioso se é aquele que o trabalhador professa - pouco importa.

Já para a questão do segundo direito, de ser tratado como igual, o tratamento privilegiado dado a uma certa religião representa uma violação. Mesmo se desconsiderar-se o exercício do direito de culto (que novamente também poderia se enquadrar no primeiro, o direito de igual tratamento), a preferência por uma tradição religiosa em detrimento das demais representa uma clara violação do direito de ser tratado como igual, vez que hierarquiza as religiões. E, para Dworkin, isto é muito mais sério, por se tratar de um direito fundamental:

Proponho que o direito a ser tratado como igual deve ser visto como fundamental na concepção liberal de igualdade, e que o direito mais restritivo a igual tratamento somente tenha validade naquelas circunstâncias específicas nas quais, por alguma razão especial, ele decorra do direito mais fundamental [...]. Proponho igualmente que os direitos individuais a diferentes liberdades devam ser reconhecidos somente quando se puder mostrar que o direito fundamental a ser tratado como igual exige tais direitos. Se isso for correto, o direito a diferentes liberdades não entra em conflito com nenhum suposto direito à igualdade concorrente; ao contrário, decorre de uma concepção de igualdade que se admite como mais fundamental (DWORKIN, 2007, p. 421).

Ciências Sociais Aplicadas em Revista, v. 20, n. 38, p. 186-202, semestral, janeiro-junho, 2020. 
Sem dúvida, fica claro que, para Dworkin, o direito a igualdade é violado com o atual modelo pátrio de feriados religiosos. Dworkin (2013, p. 113) aponta ainda que nas vezes em que certas religiões, teísticas, impõem deveres e responsabilidades, não apenas de adoração, mas sociais, e um governo que proíbe pessoas de respeitar tais deveres insulta profundamente sua dignidade e autorrespeito.

Demonstrada tal violação, resta o problema de como esta poderia ser solucionada. Para tal, vários modos se apresentam, tanto compatíveis e não compatíveis com o modelo do estado brasileiro. Nesta linha, Lomtatidze (2011, p. 8-9) irá apresentar uma classificação de modelos, alguns dos quais podem ser descartados de plano: teocracia absoluta, religião estabelecida pelo Estado, igrejas endossadas pelo Estado e o modelo de hostilidade e perseguição aberta.

Lomtatidze, ainda, oferece um último modelo que, apesar de classificar como incompatível com o liberalismo, pode em parte ser compatível com o constitucionalismo pátrio: regime de cooperação. Este é um modelo amplo, que vai desde o Estado financiando certas atividades religiosas (o que para Blancarte (2012) violaria a laicidade), até um tratamento em que se endossa igrejas sem endossar religiões. Neste último caso, seria um modelo em que se trataria todas as diferentes religiões de maneira igual. Porém, como diferentes religiões têm necessidades diferentes, esta cooperação criaria problemas para se tornar o tratamento igualitário. Assim, apesar de concepção de tratamento não diferenciado, este seria virtualmente impossível, criando problemas de igualdade e justiça para o Estado (LOMTATIDZE, 2011, p. 10-11), causando uma inevitável violação ao direito fundamental de ser tratado como igual (DWORKIN, 2007, p. 421).

Seguem-se os modelos compatíveis com o liberalismo. O primeiro seria uma variante do modelo de igreja estabelecida pelo Estado, mas com a aplicação de princípios liberais que garantam tratamento igual às outras religiões como, por exemplo, ocorre no Reino Unido (LOMTATIDZE, 2011, p. 12). Entretanto, tal modelo apresenta dois problemas: além de violar o direito de ser tratado como igual, é inconstitucional no Brasil em face do artigo 19, I da Constituição Federal (BRASIL, 1988) e, assim, não merece maiores considerações.

Outro modelo é o regime de separação, o mais rígido dentro os modelos liberais, onde o Estado insiste em uma separação rígida entre Estado e Igreja, e qualquer exceção de natureza religiosa é considerada inapropriada. $\mathrm{O}$ direito à liberdade religiosa individual é garantido e preservado, porém qualquer manifestação do Estado seria proibida, até mesmo o estabelecimento de feriados religiosos (LOMTATIDZE, 2011, p. 13). Tal modelo poderia ser considerado, por um 
lado, como um ideal de laicidade, porém, ao mesmo tempo, poderia vir a ser uma violação à liberdade de culto e crença, vez que interferiria no exercício de prescrições religiosas.

Um exemplo do modelo do regime de separação é o francês, o laicite. O problema, entretanto, é que, neste modelo, as vezes a liberdade religiosa, a igualdade entre os cidadãos, e a neutralidade do estado se tornam princípios conflitantes. Isto ocorre pois certos cidadãos irão ter necessidades de direitos ou concessões especiais como requisitos a alcançar o igual exercício de sua liberdade religiosa (LOMTATIDZE, 2011, p. 13).

O último ${ }^{5}$ modelo apresentado é o regime acomodacionista. Neste, apesar do Estado insistir na separação Estado e Religião, é adotada uma atitude de neutralidade benigna, uma cooperação onde o Estado reconhece a importância da religião como parte da cultura, e permite exceções como a existência de feriados religiosos (LOMTATIDZE, 2011, p. 12). Tal modelo é o que mais se aproxima da atual realidade pátria, desconsiderando-se a exclusividade dos feriados Católicos. Medidas de reequilíbrio poderiam, ao menos teoricamente, ser adotadas de maneira a neutralizar o poder de influência (DWORKIN, 2005, p. 79) do contexto de preponderância histórica (MACHADO, 2002, p. 154) que gerou a atual inequidade. Assim, tanto a garantia de igualdade quando do direito de culto poderiam ser preservados.

Tal escolha entre os dois modelos apontados por Lomtatidze que são compatíveis com a ideia de igualdade e a ordem constitucional pátria traria, ainda, outras consequências, o que agrava ainda mais o problema. Se, por um lado, o regime de separação não oferece previsões para nenhuma religião, o acomodacionista visa oferece-las para todas. Ainda, se tal realidade fosse possível (o que por si só seria um desafio hercúleo, dado não apenas o número de religiões existentes, como o surgimento de novas religiões e denominações) os impactos econômicos (para se citar apenas uma consequência colateral) seriam imensos. A criação de um único novo feriado estadual foi o suficiente para, baseado unicamente no argumento econômico, ser proposta e conhecida uma ação direta de inconstitucionalidade (BRASIL. Supremo Tribunal Federal, 2017).

Não obstante as dificuldades, o problema da desigualdade de tratamento existe, e deverá, na busca da laicidade e na garantia do direito fundamental à liberdade religiosa (MACHADO, 2002), ser enfrentado.

\footnotetext{
${ }^{5}$ A ordem dos modelos apresentados por Lomtatidze foi alterada, de maneira a facilidade a sua análise no presente trabalho.
}

Ciências Sociais Aplicadas em Revista, v. 20, n. 38, p. 186-202, semestral, janeiro-junho, 2020. 


\section{CONSIDERAÇÕES FINAIS}

O presente artigo visitou a história dos feriados e dias sagrados oficiais, através de uma revisão dos textos constitucionais e legislações infraconstitucionais. Observou-se que, apesar de referências explícitas a feriados terem sido expurgadas do texto da atual constituição, estes ainda se encontram presentes indiretamente, por referência, bem como na ordem legal vigente, com especial destaque para o dia 12 de outubro, Consagrado a Nossa Senhora Aparecida, Padroeira do Brasil. A presença de uma data consagrada (ato religioso) para um determinado ícone de uma determinada religião (ou grupo de religiões: matriz cristã) é inegável.

Em seguida, na esteira da observação de um feriado que aponta para uma preponderância de um grupo religioso, os feriados foram estudados no contexto de direito trabalhista e como manifestação cultural. Observou-se que a coincidência de feriados não-religiosos com datas religiosas cristãs não é acidental, ficando evidente um tratamento diferencial preferenciado a esse bloco religioso em detrimento dos demais. Como foi observado, ainda que existam outros feriados de homenagens tanto na esfera federal como estadual de natureza não religiosa, todos os feriados religiosos são ligados à tradição da Igreja Católica. A seletividade é, assim amplamente demonstrada.

Finalmente, através da proposta de Ana Lomtatidze e com a utilizado do referencial teórico de Ronald Dworkin, foram analisados possíveis modelos adequados ao constitucionalismo brasileiro, chegando-se finalmente a dois modelos que seriam compatíveis, porém com dificuldades resultantes. Fica claro, na presente pesquisa, a impossibilidade da simples adoção de um modelo importado, sendo imprescindível o desenvolvimento de um modelo de laicidade pátrio, constitucionalmente adequado, que inclua as peculiaridades brasileiras, algo que não existe. Para tal fim, novas pesquisas se fazem necessárias.

\section{REFERÊNCIAS}

ACRE. Lei n. 1.538, de 29 de janeiro de 2004. Institui feriado no Estado do Acre o dia 23 de janeiro, como o dia dos Evangélicos. Disponível em: http://www.al.ac.leg.br/leis/wpcontent/uploads/2014/09/Lei1538.pdf. Acesso em: 11 ago. 2017.
ALAGOAS. Lei Estadual 5.508/1993. Dispõe sobre Feriado Estadual no Dia 24 de Junho, Consagrado
a
São
João.
Disponível
em: 
http://web.archive.org/web/20161130192525/http://www.gabinetecivil.al.gov.br/legislacao/leis/le is-ordinarias/1993/lei\%20ordinaria-5508. Acesso em: 23 set. 2019.

BLANCARTE, Roberto J. ¿Cómo podemos medir la laicidad? Estudos Sociológicos. El Colegio de Mexico. v. 30 n. 88 p. 233-247, jan/apr, 2012.

BOSISIO, Izabella. Feriados no Brasil: A presença da religião no calendário oficial e sua regulação. In: ARAÚJO, Melvina; CUNHA, Christina Vital da (org.). Religião e Conflito. Curitiba: Prismas, 2016.

BRASIL. Constituição da República dos Estados Unidos do Brasil (de 10 de novembro de 1937). Disponível em: http://www.planalto.gov.br/ccivil_03/constituicao/constituicao37.htm. Acesso em: 4 ago. 2017.

BRASIL. Constituição da República Federativa do Brasil de 1988. Disponível em: http://www.planalto.gov.br/ccivil_03/constituicao/ConstituicaoCompilado.htm. Acesso em:4 ago. 2017.

BRASIL. Decreto $\mathrm{n}^{\circ} 27.048$ de 12 de agosto de 1949. Aprova o regulamento da Lei $\mathbf{n}^{\mathbf{0}} \mathbf{6 0 5}$, de 5 de janeiro de 1949, que dispõe sôbre o repouso semanal remunerado e o pagamento de salário nos dias feriados civis e religiosos. Disponível em: http://www.planalto.gov.br/ccivil_03/decreto/1930-1949/D27048.htm. Acesso em: 4 de ago. 2017.

BRASIL. Decreto-Lei $n^{\circ} 5.452$, de $1^{\circ}$ de maio de 1943 . Aprova a Consolidação das Leis do Trabalho. Disponível em: http://www.planalto.gov.br/ccivil_03/decretolei/Del5452compilado.htm. Acesso em: 4 ago. 2017.

BRASIL. Emenda Constitucional $\mathrm{n}^{\circ} 1$, de 17 de outubro de 1969. Edita o novo texto da Constituição Federal de 24 de janeiro de 1967. Disponível em: http://www.planalto.gov.br/ccivil_03/constituicao/Emendas/Emc_anterior1988/emc01-69.htm.

Acesso em: 4 ago. 2017.

BRASIL. Lei ${ }^{\circ} 10.607$, de 19 de dezembro de 2002. Dá nova redação ao art. 10 da Lei no 662 , de 6 de abril de 1949, que "declara feriados nacionais os dias $1^{\circ}$ de janeiro, $1^{\circ}$ de maio, 7 de setembro, 15 de novembro e 25 de dezembro", e dá outras providências. Disponível em: http://www.planalto.gov.br/ccivil_03/leis/2002/L10607.htm. Acesso em: 4 ago. 2017.

BRASIL. Lei $\mathrm{n}^{\circ} 11.635$, de 27 de dezembro de 2007. Institui o Dia Nacional de Combate à Intolerância Religiosa. Disponível em: http://www.planalto.gov.br/ccivil_03/_ato20072010/2007/lei/111635.htm. Acesso em: 11 ago. 2017.

BRASIL. Lei $n^{\circ}$ 6.802, de 30 de junho de 1980. Declara Feriado Nacional o Dia 12 de outubro, Consagrado a Nossa Senhora Aparecida, Padroeira do Brasil. Disponível em: http://www.planalto.gov.br/ccivil_03/leis/L6802.htm. Acesso em: 4 ago. 2017.

BRASIL. Lei $\mathrm{n}^{\circ}$ 605, de 5 de janeiro de 1949. Repouso semanal remunerado e o pagamento de salário nos dias feriados civis e religiosos. Disponível em: http://www.planalto.gov.br/ccivil_03/leis/L0605.htm. Acesso em: 4 de ago. 2017. 
BRASIL. Lei $n^{\circ}$ 662, de 6 de abril de 1949. Declara feriados nacionais os dias $\mathbf{1}^{\circ}$ de janeiro, $\mathbf{1}^{\circ}$ de maio, 7 de setembro, 15 de novembro e 25 de dezembro. Disponível em: http://www.planalto.gov.br/ccivil_03/leis/L0662.htm. Acesso em: 4 ago. 2017.

BRASIL. Lei $\mathrm{n}^{\circ}$ 9.093, de 12 de setembro de 1995. Dispõe sobre feriados. Disponível em: http://www.planalto.gov.br/ccivil_03/leis/L9093.htm. Acesso em: 4 ago. 2017.

BRASIL. Ministério do Planejamento, Desenvolvimento e Gestão. Portaria ${ }^{\circ} 369$, de 29 de novembro de 2016. Divulga os dias de feriados nacionais e estabelece os dias de ponto facultativo do ano de 2017, para cumprimento pelos órgãos e entidades da Administração Pública federal direta, autárquica e fundacional do Poder Executivo. Diário Oficial da União, Brasília, DF, 30 nov. 2016. Seção 1, p. 78.

BRASIL. Supremo Tribunal Federal. Ação Direta de Inconstitucionalidade $\mathbf{n}^{\circ}$ 4.092. Rel. Min Celso de Mello. Disponível em: http://www.stf.jus.br/portal/processo/verProcessoAndamento.asp?incidente=2624787. Acesso em: 11 ago. 2017.

Chabad-Lubavitch Media Center. Shabbat: An Island in Time. Disponível em: http://www.chabad.org/library/article_cdo/aid/253215/jewish/Shabbat.htm. Acesso em: 8 ago. 2017.

DELGADO, Mauricio Godinho. Curso de Direito do Trabalho. 16. ed. rev. e ampl. São Paulo: LTr, 2017.

DISTRITO FEDERAL. Lei n. 893, de 27 de julho de 1995. Institui, no Distrito Federal, o Dia do Evangélico e dá outras providências. Disponível em: http://legislacao.cl.df.gov.br/Legislacao/buscarLei-4382!buscarLei.action. Acesso em: 11 ago. 2017.

DISTRITO FEDERAL. Lei n. 963, de 4 de dezembro de 1995. Institui, no âmbito do Distrito Federal, feriado no dia 30 de novembro. Disponível em: http://legislacao.cl.df.gov.br/Legislacao/buscarLei-4312!buscarLei.action. Acesso em: 11 ago. 2017.

DWORKIN, Ronald. A Virtude Soberana: a teoria e a prática da igualdade. Trad. Jussara Simões. São Paulo: Martins Fontes, 2005.

DWORKIN, Ronald. Domínio da Vida: aborto, eutanásia e liberdades individuais. Trad. Jefferson Luiz Camargo. 2. ed. São Paulo: WMF Martins Fontes, 2009.

DWORKIN, Ronald. Levando os Direitos a Sério. São Paulo: Martins Fontes, 2007.

DWORKIN, Ronald. Religion without God. Cambridge, MA: Harvard University Press, 2013.

FERNANDES, Bernardo Gonçalves. Curso de Direito Constitucional. 9. ed. rev., ampl. e atual. Salvador: Juspodivm, 2017. 
LOMTATIDZE, Ana. Should Religion be Used in Politics? A Theoretical Discussion. 2011. 54f. Dissertation (Masters in Arts) - Department of Political Science, Central European University, Budapest, Hungary, 2011.

MACHADO, Jónatas. A liberdade religiosa na perspectiva dos direitos fundamentais. Revista Portuguesa de Ciência das Religiões. Universidade Lusófona de Humanidades e Tecnologias, ano I, n. 1, p. 149-154, 2002.

MICHAELIS. Dicionário de Língua Portuguesa. Editora Melhoramentos. Disponível em: http://michaelis.uol.com.br/busca?r=0\&f=\&t=\&palavra=feriado. Acesso em: 4 ago. 2017.

MIR, Luís. Partido de Deus: Fé, Poder e Política. São Paulo: Alaúde, 2007.

PARAÍBA. Lei n. 3.489, de 30 de agosto de 1967. Dispõe sobre símbolos e feriados estaduais. Disponível em: http://sapl.al.pb.leg.br:8080/sapl/sapl_documentos/norma_juridica/2945_texto_integral. Acesso em: 11 ago. 2017.

RIO DE JANEIRO (Estado). Lei n. 5.198, de 5 de março de 2008. Institui feriado estadual, dia 23 de abril, "Dia de São Jorge". Disponível em: http://alerjln1.alerj.rj.gov.br/CONTLEI.NSF/c8aa0900025feef6032564ec0060dfff/1baf90ca125ff 96f8325740a00776600. Acesso em: 11 ago. 2017.

Shamash. The Jewish Network. Frequently Asked Questions and Answers: Shabbat Observance. Disponível em: http://shamash.org/lists/scj-faq/HTML/faq/07-index.html. Acesso em: 8 ago. 2017. 